\title{
Older Canadians at risk of undernourishment
}

A third of all Canadians aged 65 and older are at risk of being undernourished, according to a new Statistics Canada study.

More than 4.1 million older Canadians, or $34 \%$ overall, are on the cusp of malnutrition, indicate the results of the 2008/2009 Canadian Community Health Survey — Healthy Aging. Without intervention, these people are at greater risk of frailty, falls, hospitalization, institutionalization and death, the study says.

Statistics Canada released a study based on the survey in its March 2013 Health Reports (www.statcan.gc.ca/pub/82-003 -x/2013003/article/11773-eng .htm). Authors Pamela RamageMorin and Didier Garriguet used the Seniors in the Community Risk Evaluation for Eating and Nutrition tool, which uses a points scale to assess respondents' nutritional risk factors based on their responses. The authors surveyed 15660 people aged 65 and older (6334 men and 9335 women), with an average age of 77 .

A complex set of social and economic circumstances, as well as physical and mental health, all contribute to nutritional risk. The authors cite factors including diminished appetite, impaired taste and smell, diseases and medication that interfere with the ingestion, absorption and metabolism of food, reduced mobility that limits food shopping and meal preparation, poverty, eating alone, depression, grief and loneliness.

At the Queensway-Carleton Hospital in Ottawa, Ontario, registered dietician Sherri Elder sees many older patients who are undernourished. Some are underweight and some are overweight, she adds.

"We see the whole spectrum of issues - from not enough food, to lacking support from friends and family, to not enough money, to issues with dementia and the aging population," Elder says. "The aging population has a lot of poverty, especially women and women living alone. So if they're lacking money...they may not be buying fresh fruits and vegetables, dairy or meats."

The Statistics Canada survey meagain and how often respondents skipped sured nutritional risk by weight loss or

tions. They are also more likely to diet because more women than men are concerned with body image in that age range, explain the authors.

About half (49\%) of people living alone were at nutritional risk, compared with $28 \%$ of those who lived with a spouse or companion. The study also found that $44 \%$ of older people with a moderate or severe disability were at risk, compared to $27 \%$ of those with no disability. Depression also had a big impact on nutritional risk; those who were depressed were nearly twice as likely $(62 \%)$ to be at nutritional risk versus those who were not depressed (33\%).

Older people who are depressed are less motivated to cook meals, and dementia may also reduce their ability to do so, says Azad. "They need more home assistance with shopping and making meals, and some need to locate to a retirement home."

Social support, such as having a drimeals, ate fewer than two servings of fruit and vegetables daily, ate alone or found cooking a chore.

Weight changes should be a particular red flag for health care providers, says Dr. Nahid Azad, professor of geriatric medicine at the University of Ottawa in Ontario and a geriatric specialist at Ottawa Hospital's Civic Campus.

"Medical problems that result in hospital admission originate from the fact that they were undernourished, they were weak, or their immune system was poor," she says. "We treat them for their acute problem, but we find that the root cause is because they were socially isolated and losing weight. Then they become dizzy and fall and break bones."

Women are more at risk of undernourishment $(38 \%)$ than men $(29 \%)$. Postmenopausal women are more likely to experience weight fluctua- ver to make trips to the grocery store or a helper to prepare meals, is important in improving nutrition in seniors, the study advises.

Reaching out to older people in the community is the best way to encourage better nutrition, says Elder, praising the role of antipoverty groups, family physicians, meal programs and churches and community centres.

The nutrition of older people will continue to grow in importance, especially as baby boomers age, says Azad. "We have to be prepared with education about proper nourishment and also the social assistance that is needed to make sure they have access to adequate nourishment," she says. "Good nourishment is one of the pillars of proper care." - Hanna Lange-Chenier, CMAJ

CMAJ 2013. DOI:10.1503/cmaj.109-4482 